\title{
Gook-Sup Song \\ Buttock temperature in a sedentary posture on plywood flooring of varying thickness over the ONDOL heating system
}

\begin{abstract}
This study investigated the thermophysiological responses of healthy subjects that sat on the plywood covering of the ONDOL floor heating system. Environmental chambers were constructed for this study, wherein ambient temperature, and wall and ceiling surface temperature were controlled at $24^{\circ} \mathrm{C}$, and relative humidity was $50 \%$. The temperature of supply water $\left(t_{\mathrm{sw}}\right)$ flowing into the floor coil was altered from $15^{\circ} \mathrm{C}$ to $40^{\circ} \mathrm{C}$ at $5^{\circ} \mathrm{C}$ intervals. The floor covering materials used in this experiment were mortar and three types of plywood with thicknesses of 2.7, 7.5, and $12 \mathrm{~mm}$. The floor surface temperatures $\left(t_{\mathrm{f}}\right)$ and the skin temperatures of eight subjects were measured while they were sitting on the floor. Buttock temperature, in particular, was monitored. This experiment yielded the following results: (1) $t_{\mathrm{f}}$ was $17.0^{\circ}-35.2^{\circ} \mathrm{C}$ on mortar finishing and $19.1^{\circ}-$ $30.2^{\circ} \mathrm{C}$ on $12-\mathrm{mm}$ plywood covering; (2) the buttocks skin temperature increased with $t_{\mathrm{sw}}$ higher than $30^{\circ} \mathrm{C}$ on mortar finishing and for $t_{\mathrm{sw}}$ higher than $30^{\circ}, 25^{\circ}$, and $20^{\circ}$ on 2.7-, $7.5-$, and $12-\mathrm{mm}$ plywood finishing, respectively; (3) the differences of buttock temperature when $t_{\mathrm{sw}}$ was varied between $15^{\circ}$ and $40^{\circ} \mathrm{C}$ were $11.4^{\circ} \mathrm{C}$ on mortar, $7.9^{\circ} \mathrm{C}$ on 2.7 $\mathrm{mm}$ plywood, $6.5^{\circ} \mathrm{C}$ on $7.5-\mathrm{mm}$ plywood, and $5.0^{\circ} \mathrm{C}$ on 12-mm plywood; (4) using regression analysis, the neutral point temperature of buttocks was determined to be $32.8^{\circ} \mathrm{C}$.
\end{abstract}

Key words Skin temperature - Floor covering - ONDOL . Thermal comfort

\section{G.-S. Song $(\bowtie)$}

Department of Architecture, Bucheon College, 424 Simcock-Dong Wonmi-Gu Bucheon-Si Geongki-Do 421-735, South Korea

Tel. +82-32-610-3306; Fax +82-32-610-3223

e-mail: songsup@bc.ac.kr

Part of this report was presented at the 53rd Annual Meeting of the Japan Wood Research Society, Fukuoka, Japan, March 2003

\section{Introduction}

Because most Koreans sit or lie on the floor of their residential buildings, their buttocks are in contact with floor finishing materials. These materials affect the level of thermal comfort of the residents. A number of studies have been performed on how human skin responds when it comes into contact with cold and hot materials. Chen, ${ }^{1}$ and Lawrence and $\mathrm{Bull}^{2}$ investigated the reaction of human skin when fingers touched metal cubes and gripped vertical bars (wood, nylon, stone, steel, and aluminum materials). Wang $^{3-4}$ examined the thermal sensation of the feet and palms that come into contact with decorative interior materials. Banhidi ${ }^{5}$ introduced the works which investigated the changes in sole temperature using an artificial leg. He concluded that the smaller the contact coefficient (heat penetration coefficient) of the floor, the more favorable it is for the sole. Therefore, a smaller contact coefficient means a higher level of thermal comfort. Olesen ${ }^{6}$ proposed that the temperature for a wooden floor should be between $23^{\circ}$ and $28^{\circ} \mathrm{C}$ and between $26^{\circ}$ and $28.5^{\circ} \mathrm{C}$ for a concrete floor. Fanger ${ }^{7}$ compared the contact coefficient of floor materials to evaluate the characteristics of a suitable floor material that comes into contact with bare feet. He suggested the following comfortable temperature ranges: $29^{\circ}-32^{\circ} \mathrm{C}$ for steel, $27^{\circ}-34^{\circ} \mathrm{C}$ for concrete, $17^{\circ}-39^{\circ} \mathrm{C}$ for pine, and $5^{\circ}-$ $42^{\circ} \mathrm{C}$ for cork. Song ${ }^{8}$ compared comfortable temperature ranges among various finishing materials that come into contact with buttocks (mortar, lauan wood, clay, pine wood, steel panel, and urethane board). He concluded that wooden flooring has a wider comfortable temperature range than other flooring materials.

These previous studies revealed that wood- and corkfinished floorings have wide comfortable temperature ranges. In South Korea, the covering material of the ONDOL floor heating system has been changed from floor paper to a wood covering in recent years. If the wood covering is very thin, its characteristics will be similar to that of a mortar-finished covering. However, the effect of floor thickness is unknown. This study was therefore performed 
to determine the physiological response of the human body on wooden floors of varied thickness.

\section{Experimental}

Environmental chamber and floor construction

Two environmental chambers were constructed next to each other for this study. Each chamber had the same size: $2.4($ width $) \times 2.4($ depth $) \times 2.3 \mathrm{~m}($ height $)$. Figure 1 shows the floor plan of these chambers. The first was called the preliminary chamber, where subjects stayed to keep their body temperatures in a stable condition. The other was the main experimental chamber, where ambient temperature and

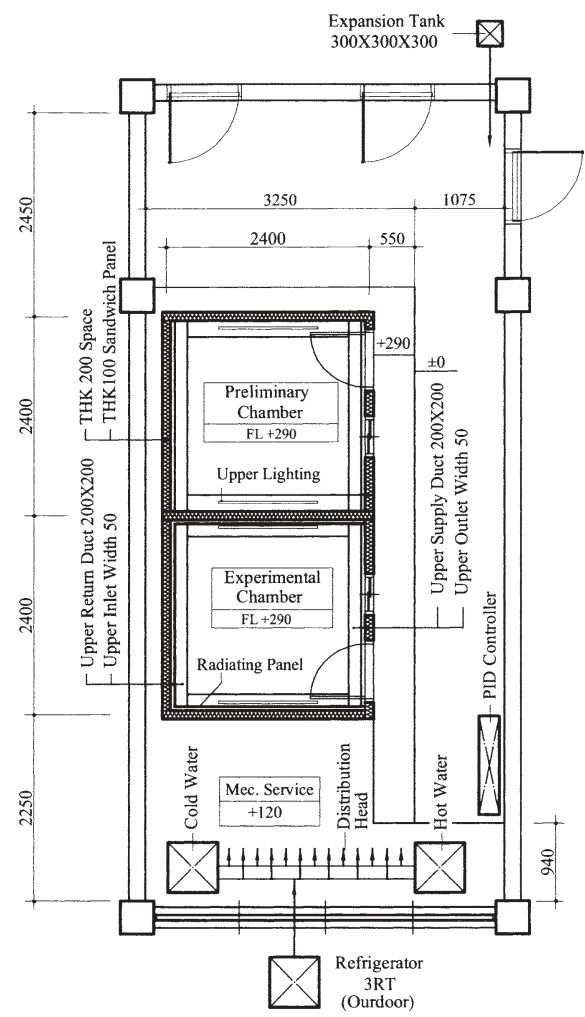

Fig. 1. Plan of experimental chamber relative humidity were controlled. The ceiling of the experimental chamber was fitted with an air handling unit (AHU) with a cooling coil, reheating coil, and humidifier. The radiant temperatures of the ceiling and wall were controlled with $15-\mathrm{mm}$ diameter copper pipe spaced at $150 \mathrm{~mm}$ on the wall and ceiling and was covered with $1.5-\mathrm{mm}$ thick steel panel.

The floor system consisted of the insulation layer, thermal storage layer, and covering layer. The covering materials used in this experiment were mortar and three types of plywood with thicknesses of $2.7,7.5$, and $12 \mathrm{~mm}$. The heat conductivity of the plywood used in this experiment was $0.14 \mathrm{~W} / \mathrm{m} \cdot \mathrm{K}$, the specific heat was $920 \mathrm{~J} / \mathrm{m}^{3} \cdot \mathrm{K}$, and the density was $530 \mathrm{~kg} / \mathrm{m}^{3}$. To control floor temperature, a $15-\mathrm{mm}$ diameter copper pipe was installed at $50-\mathrm{mm}$ spacing in 50 $\mathrm{mm}$ thick mortar. Figure 2 illustrates the floor construction.

A 3-way control valve (VMP43.14), actuator (SSB61), and PID controller (RWX62.7032 and RWC62) were installed to automatically control temperature and humidity. These devices were produced by Simense (Germany).

\section{Subjects}

Eight physically healthy college students participated in this experiment (four men and four women). After explaining the process to them, they all agreed and conformed to the procedure. Table 1 shows the particulars of each subject. They were asked to change into training shirts and trousers, keeping their undergarments. Socks were not worn because most Koreans do not wear them at home. The "clo" value was calculated as 0.45 and this value corresponds to light clothes.

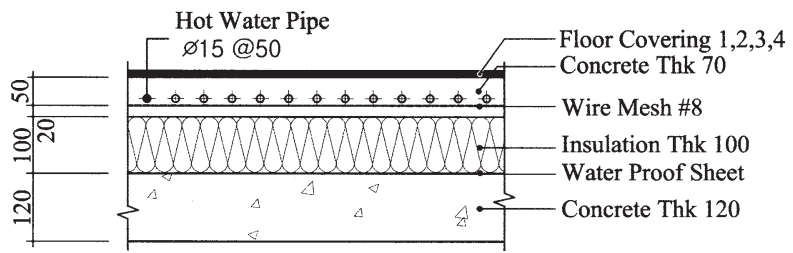

Fig. 2. Section drawing of floor construction

Table 1. Particulars of each subject

\begin{tabular}{llllll}
\hline Subject & Sex & Age (years) & Height $(\mathrm{cm})$ & Weight $(\mathrm{kg})$ & $A_{\mathrm{D}}\left(\mathrm{m}^{2}\right)$ \\
\hline (A) JMS & Male & 19 & 174 & 67 & 1.802 \\
(B) KJH & Male & 19 & 168 & 60 & 1.677 \\
(C) LDK & Male & 30 & 169 & 60 & 1.684 \\
(D) LKS & Male & 19 & 172 & 57 & 1.669 \\
(E) SYJ & Female & 21 & 163 & 55 & 1.581 \\
(F) CGS & Female & 19 & 168 & 66 & 1.746 \\
(G) CMH & Female & 24 & 174 & 63 & 1.756 \\
(H) KHS & Female & 22 & 172 & 58 & 1.681 \\
Mean & & $21.6( \pm 1.36)$ & $170.0( \pm 1.32)$ & $60.7( \pm 1.51)$ & $1.700( \pm 0.02)$ \\
\hline
\end{tabular}

Standard error shown in parentheses

$A_{\text {D }}$, Nude body surface area by Dubois equation 
Table 2. Water temperatures used and dates of tests (2002)

\begin{tabular}{lllll}
\hline$t_{\text {sw }}$ & Mortar & $\begin{array}{l}2.7-\mathrm{mm} \\
\text { plywood }\end{array}$ & $\begin{array}{l}\text { 7.5-mm } \\
\text { plywood }\end{array}$ & $\begin{array}{l}12-\mathrm{mm} \\
\text { plywood }\end{array}$ \\
\hline $15^{\circ} \mathrm{C}$ & Oct. 22 & Nov. 09 & Dec. 15 & Dec. 23 \\
$20^{\circ} \mathrm{C}$ & Oct. 25 & Nov. 28 & Dec. 14 & Dec. 22 \\
$25^{\circ} \mathrm{C}$ & Oct. 28 & Nov. 23 & Dec. 13 & Dec. 21 \\
$30^{\circ} \mathrm{C}$ & Oct. 30 & Nov. 21 & Dec. 06 & Dec. 20 \\
$35^{\circ} \mathrm{C}$ & Nov. 04 & Nov. 15 & Dec. 04 & Dec. 19 \\
$40^{\circ} \mathrm{C}$ & Nov. 09 & Nov. 11 & Dec. 02 & Dec. 17 \\
\hline
\end{tabular}

$t_{\mathrm{sw}}$, Temperature of supply water

\section{Measuring environments}

A thermo neutral temperature of $24^{\circ} \mathrm{C}$ was maintained in the preliminary chamber. The main experimental chamber was controlled at $24^{\circ} \mathrm{C}$ (the ambient and surface temperature of wall and ceiling), $50 \%$ relative humidity, and $0.2 \mathrm{~m} /$ $\mathrm{s}$ air velocity. The temperature of the supply water $\left(t_{\mathrm{sw}}\right)$ flowing into the floor coil was adjusted from $15^{\circ}$ to $40^{\circ} \mathrm{C}$ at $5^{\circ} \mathrm{C}$ intervals.

\section{Experimental procedure}

Tests were performed at the laboratory of Bucheon College from October 22 to December 23, 2002. Table 2 shows the dates when temperatures were taken. When the experiment started, participants were asked to enter the preliminary chamber one by one, change into training shirts and trousers, and attach the probes of a skin thermometer with medical tape to eight points on the body: forehead, abdomen, forearm, thigh, calf, instep, back of hand, and buttocks. They sat for $20 \mathrm{~min}$ on a chair with openings that allowed air to flow freely. After $20 \mathrm{~min}$, they were moved to the main chamber. They were instructed to sit on the floor and were required to keep their buttocks close to the surface material. Slight movement of legs was allowed when the legs began to feel numb. Subjects were given a book to read while they participated in the experiments.

Inside the preliminary chamber, skin temperatures of eight body points were measured for $20 \mathrm{~min}$ at 30 -s intervals using a precision thermometer (Gram, Model: LT-8). In the main chamber, skin temperatures were measured for $50 \mathrm{~min}$, also at 30 -s intervals. After every $10 \mathrm{~min}$, each participant was asked to rate the thermal sensation they felt on a scale of 0 to 8 ( 0 : very cold, 1: cold, 2: cool, 3: slightly cool, 4: neutral, 5: slightly warm, 6: warm, 7: hot, 8: very hot).

Mean skin temperature was calculated by modifying the original 7-point method. In this experiment, the buttock temperatures were measured as they came into contact with the floor surface area. Subtracting the buttock contact factor from the original thigh factor gives the thigh surface factor. Korean and Japanese researchers studied the contact surface area and suggested the following weighing factors: $3.39 \%, 2.19 \%, 2.71 \%$, and $2.45 \%{ }^{9,10}$ in Japan, and $3.37 \%{ }^{11}$ in Korea. The result of the study conducted by Yoon $^{11}$ was adopted in this research because it investigated the traditional sedentary posture of Koreans.
Table 3. Mean globe temperature $\left({ }^{\circ} \mathrm{C}\right)$ of experimental chamber

\begin{tabular}{lllll}
\hline$t_{\mathrm{sw}}$ & Mortar & $\begin{array}{l}2.7-\mathrm{mm} \\
\text { plywood }\end{array}$ & $\begin{array}{l}7.5-\mathrm{mm} \\
\text { plywood }\end{array}$ & $\begin{array}{l}12-\mathrm{mm} \\
\text { plywood }\end{array}$ \\
\hline $15^{\circ} \mathrm{C}$ & $23.1( \pm 0.004)$ & $22.9( \pm 0.003)$ & $23.0( \pm 0.001)$ & $23.3( \pm 0.002)$ \\
$20^{\circ} \mathrm{C}$ & $23.1( \pm 0.007)$ & $23.3( \pm 0.011)$ & $23.4( \pm 0.002)$ & $23.5( \pm 0.003)$ \\
$25^{\circ} \mathrm{C}$ & $23.5( \pm 0.002)$ & $24.0( \pm 0.004)$ & $23.8( \pm 0.003)$ & $23.6( \pm 0.001)$ \\
$30^{\circ} \mathrm{C}$ & $23.9( \pm 0.003)$ & $24.1( \pm 0.004)$ & $23.9( \pm 0.001)$ & $23.8( \pm 0.001)$ \\
$35^{\circ} \mathrm{C}$ & $23.8( \pm 0.003)$ & $23.8( \pm 0.01)$ & $23.9( \pm 0.004)$ & $23.9( \pm 0.006)$ \\
$40^{\circ} \mathrm{C}$ & $24.2( \pm 0.002)$ & $23.7( \pm 0.007)$ & $23.9( \pm 0.011)$ & $23.7( \pm 0.009)$ \\
\hline
\end{tabular}

Table 4. Mean floor surface temperature $\left({ }^{\circ} \mathrm{C}\right)$

\begin{tabular}{lllll}
\hline$t_{\mathrm{sw}}$ & Mortar & $\begin{array}{l}2.7-\mathrm{mm} \\
\text { plywood }\end{array}$ & $\begin{array}{l}7.5-\mathrm{mm} \\
\text { plywood }\end{array}$ & $\begin{array}{l}12-\mathrm{mm} \\
\text { plywood }\end{array}$ \\
\hline $15^{\circ} \mathrm{C}$ & $17.0( \pm 0.001)$ & $18.2( \pm 0.002)$ & $19.5( \pm 0.0008)$ & $19.1( \pm 0.002)$ \\
$20^{\circ} \mathrm{C}$ & $20.8( \pm 0.0007)$ & $21.2( \pm 0.004)$ & $21.8( \pm 0.0009)$ & $21.3( \pm 0.004)$ \\
$25^{\circ} \mathrm{C}$ & $24.5( \pm 0.0009)$ & $24.2( \pm 0.003)$ & $24.1( \pm 0.001)$ & $23.5( \pm 0.003)$ \\
$30^{\circ} \mathrm{C}$ & $28.2( \pm 0.002)$ & $26.8( \pm 0.002)$ & $26.4( \pm 0.002)$ & $26.0( \pm 0.001)$ \\
$35^{\circ} \mathrm{C}$ & $31.8( \pm 0.0005)$ & $29.3( \pm 0.005)$ & $28.3( \pm 0.01)$ & $28.1( \pm 0.003)$ \\
$40^{\circ} \mathrm{C}$ & $35.2( \pm 0.002)$ & $32.0( \pm 0.004)$ & $30.9( \pm 0.006)$ & $30.2( \pm 0.001)$ \\
\hline
\end{tabular}

Equation 1 shows the modified mean skin temperature calculation:

$$
\begin{aligned}
\overline{t_{\mathrm{sk}}}= & 0.07 t_{\text {forehead }}+0.35 t_{\text {adomen }}+0.14 t_{\text {forearm }}+0.156 t_{\text {thigh }} \\
& +0.13 t_{\text {calf }}+0.07 t_{\text {instep }}+005 t_{\text {backofhand }}+0.034 t_{\text {buttock }}
\end{aligned}
$$

The floor surface temperatures were measured at four points for each floor covering material. Globe temperature (150-mm diameter globe and thermocouple), ambient temperature (thermocouple array, distanced vertically at $30 \mathrm{~cm}$ ), relative humidity (Kanomax, THT-N200 probe and RHD330 transducer), and air velocity (Kanomax, 2515 probe and Model 6312 air flow transducer) were measured during the experiment. A data logger (Eco, SOLAC-V 30 channel) was used to record these data.

\section{Results and discussion}

\section{Environments}

During the experiment, the globe temperatures of the environmental chamber were recorded in the range of $22.9^{\circ}-$ $23.9^{\circ} \mathrm{C}$ in spite of different floor surface temperatures as shown in Table 3. The mean air velocity was $0.2 \mathrm{~m} / \mathrm{s}$ $( \pm 0.1 \mathrm{~m} / \mathrm{s})$, and relative humidity was $48 \%( \pm 5 \%)$.

\section{Floor surface temperature}

Although the temperature of the supply water $\left(t_{\mathrm{sw}}\right)$ remained constant, the surface temperatures $\left(t_{\mathrm{f}}\right)$ were different as shown in Table 4. On the mortar finishing, temperature ranged from $17.0^{\circ} \mathrm{C}$ to $35.2^{\circ} \mathrm{C}$, while on $12-\mathrm{mm}$ plywood covering, it ranged from $19.1^{\circ} \mathrm{C}$ to $30.2^{\circ} \mathrm{C}$. Therefore, the $t_{\mathrm{f}}$ of mortar-finished floor responded more sensi- 
Table 5. Final mean skin temperature $\left({ }^{\circ} \mathrm{C}\right)$

\begin{tabular}{lllll}
\hline$t_{\mathrm{sw}}$ & Mortar & $\begin{array}{l}2.7-\mathrm{mm} \\
\text { plywood }\end{array}$ & $\begin{array}{l}7.5-\mathrm{mm} \\
\text { plywood }\end{array}$ & $\begin{array}{l}\text { 12-mm } \\
\text { plywood }\end{array}$ \\
\hline $15^{\circ} \mathrm{C}$ & $32.4(-0.5)$ & $33.5(-0.7)$ & $33.0(-0.5)$ & $33.3(-0.63)$ \\
$20^{\circ} \mathrm{C}$ & $33.5(-0.7)$ & $33.2(-0.9)$ & $33.1(-0.7)$ & $33.3(-0.42)$ \\
$25^{\circ} \mathrm{C}$ & $33.1(-0.6)$ & $33.7(-0.4)$ & $33.6(-0.2)$ & $33.5(-0.08)$ \\
$30^{\circ} \mathrm{C}$ & $33.5(-0.5)$ & $33.5(-0.3)$ & $33.9(-0.3)$ & $33.7(-0.002)$ \\
$35^{\circ} \mathrm{C}$ & $33.5(-0.3)$ & $33.6(-0.3)$ & $33.9(-0.24)$ & $33.8(-0.012)$ \\
$40^{\circ} \mathrm{C}$ & $33.8(-0.3)$ & $33.8(-0.6)$ & $33.8(-0.27)$ & $33.8(+0.28)$ \\
\hline
\end{tabular}

Values in parentheses are the difference between initial and final temperature

tively than 12-mm plywood covering. Such reaction seems to be due to the thermal resistance of plywood. Below $t_{\mathrm{sw}}$ $20^{\circ} \mathrm{C}$, the thicker plywood had a higher surface temperature. However, above $t_{\mathrm{sw}} 25^{\circ} \mathrm{C}$, the reverse became true. Hence, the thicker the plywood is, the lower the surface temperature. When the plywood covering was thick, the surface temperature was more affected by the indoor air temperature than $t_{\mathrm{sw}}$. Because the floor surface is in contact with human buttocks in a sedentary posture, it affects thermal physiology and energy consumption as people try to attain a comfortable environment.

\section{Mean skin temperature}

Table 5 shows the final mean skin temperatures $\left(\overline{t_{\mathrm{sk}}}\right)$ of the whole body. Modera ${ }^{12}$ suggested that comfortable mean skin temperature is $34.1^{\circ} \mathrm{C}$ with $50 \mathrm{kcal} / \mathrm{h} \mathrm{m}^{2}\left(58 \mathrm{~W} / \mathrm{m}^{2}\right)$ metabolism and is $31.4^{\circ} \mathrm{C}$ (men) and $30.2^{\circ} \mathrm{C}$ (women) with $150 \mathrm{kcal} / \mathrm{h} \mathrm{m}^{2}\left(174 \mathrm{~W} / \mathrm{m}^{2}\right)$ metabolism. In this experiment, mean skin temperature was in the range of $32.4^{\circ}-33.8^{\circ} \mathrm{C}$, and shows that the subjects were in a comfortable state. Because the surface area of the buttocks is about $2.19 \%-$ $3.37 \%$ of the whole body surface, indoor air temperature affects mean skin temperature more than floor surface temperature. Because this experiment focused on surface responses of the buttocks, it was necessary that the whole body be in a comfortable state.

\section{Buttock temperature changes}

The changes in buttock temperature are illustrated in Fig. 3. The plotted temperature value was derived from the average of eight subjects. On the mortar-finished floor and after cold water $\left(t_{\mathrm{sw}} 15^{\circ} \mathrm{C}\right)$ was supplied to the floor coil, the mean surface temperature $\left(t_{\mathrm{f}}\right)$ reached $17.0^{\circ} \mathrm{C}$ and buttock temperature declined sharply. This means that the buttocks lost significant heat to the mortar. However, when warm water $\left(t_{\mathrm{sw}} 40^{\circ} \mathrm{C}\right)$ was supplied to the floor coil, the buttock temperature increased to $37.2^{\circ} \mathrm{C}$.

A 2.7-mm plywood covering supplied with $t_{\mathrm{sw}} 15^{\circ} \mathrm{C}$ gave a $t_{\mathrm{f}}$ of $18.2^{\circ} \mathrm{C}$ and a buttock temperature of $28.5^{\circ} \mathrm{C}$. This was $1.2^{\circ} \mathrm{C}$ and $3.9^{\circ} \mathrm{C}$ higher, respectively, than that for mortar finishing. At $t_{\mathrm{sw}} 40^{\circ} \mathrm{C}$, however, the $t_{\mathrm{f}}$ and buttock temperature were $3.2^{\circ} \mathrm{C}$ and $0.8^{\circ} \mathrm{C}$ lower, respectively, than that for mortar finishing.

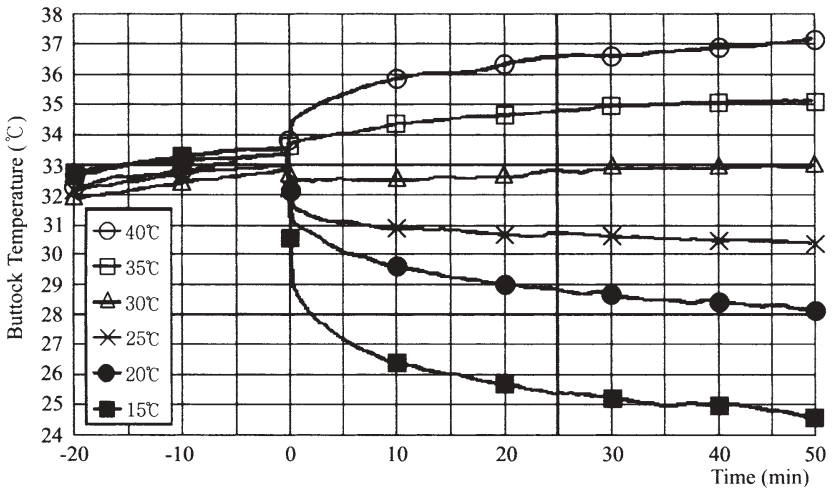

(1) On Mortar Finishing

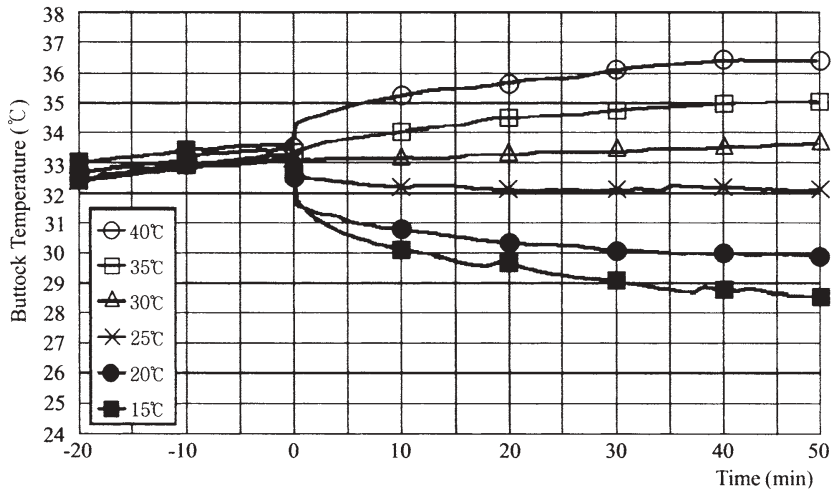

(2) On $2.7 \mathrm{~mm}$ Plywood Covering

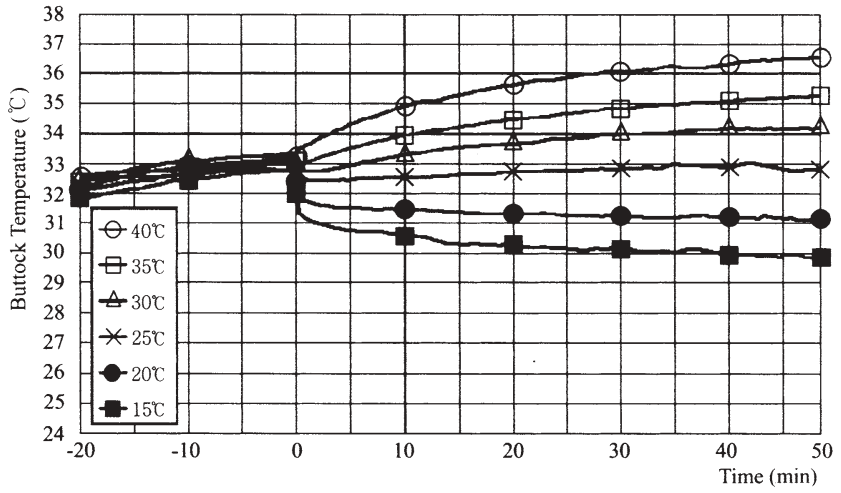

(3) On $7.5 \mathrm{~mm}$ Plywood Covering

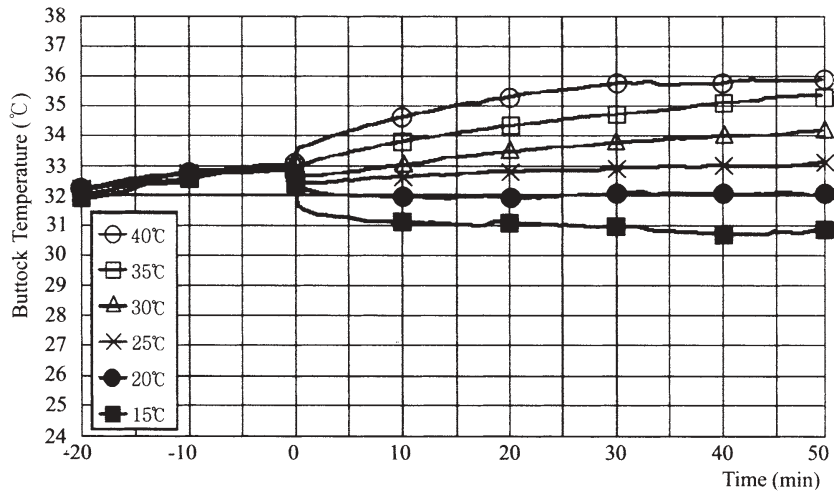

(4) On $12 \mathrm{~mm}$ Plywood Covering

Fig. 3. Changes of buttock temperature 
Table 6. Final buttock temperature $\left({ }^{\circ} \mathrm{C}\right)$

\begin{tabular}{lllll}
\hline$t_{\text {sw }}$ & Mortar & $\begin{array}{l}2.7-\mathrm{mm} \\
\text { plywood }\end{array}$ & $\begin{array}{l}\text { 7.5-mm } \\
\text { plywood }\end{array}$ & $\begin{array}{l}\text { 12-mm } \\
\text { plywood }\end{array}$ \\
\hline $15^{\circ} \mathrm{C}$ & $24.6(-8.9)$ & $28.5(-5.1)$ & $30.0(-2.8)$ & $30.9(-2.0)$ \\
$20^{\circ} \mathrm{C}$ & $28.2(-5.2)$ & $29.9(-3.3)$ & $31.1(-1.7)$ & $32.1(-1.0)$ \\
$25^{\circ} \mathrm{C}$ & $30.4(-2.6)$ & $32.1(-1.1)$ & $32.8(-0.1)$ & $33.1(+0.1)$ \\
$30^{\circ} \mathrm{C}$ & $32.9(+0.1)$ & $33.6(+0.5)$ & $34.2(+0.9)$ & $34.2(+1.3)$ \\
$35^{\circ} \mathrm{C}$ & $35.1(+1.6)$ & $35.1(+1.9)$ & $35.3(+2.1)$ & $35.4(+2.5)$ \\
$40^{\circ} \mathrm{C}$ & $37.2(+3.8)$ & $36.4(+2.9)$ & $36.6(+3.4)$ & $35.9(+2.9)$
\end{tabular}

Values in parentheses are the difference between initial and final temperature

At $t_{\mathrm{sw}} 15^{\circ} \mathrm{C}$, a $7.5-\mathrm{mm}$ plywood covering gave a mean surface temperature of $19.5^{\circ} \mathrm{C}$ and buttock temperature of $30.0^{\circ} \mathrm{C}$. When water was supplied at $t_{\mathrm{sw}} 25^{\circ} \mathrm{C}$, the $t_{\mathrm{f}}$ increased to $24.1^{\circ} \mathrm{C}$, and the buttock temperature also rose.

For 12-mm plywood covering, the temperature difference for buttocks between $t_{\mathrm{sw}} 15^{\circ} \mathrm{C}$ and $t_{\mathrm{sw}} 40^{\circ} \mathrm{C}$ was $5.0^{\circ} \mathrm{C}$. This type of plywood yielded the narrowest difference compared with the three others.

Buttock temperatures rose for $t_{\mathrm{sw}}$ values higher than $30^{\circ} \mathrm{C}$ in mortar and for $t_{\mathrm{sw}}$ values above $30^{\circ}, 25^{\circ}$, and $20^{\circ} \mathrm{C}$ for $2.7-\mathrm{mm}, 7.5-\mathrm{mm}$, and $12-\mathrm{mm}$ plywood finishing, respectively. The final buttock temperatures after the 50-min experiment are presented in Table 6. The differences in the buttock temperature for variation in $t_{\mathrm{sw}}$ between $15^{\circ}$ and $40^{\circ} \mathrm{C}$ were $12.6^{\circ}, 7.9^{\circ}, 6.6^{\circ}$, and $5.0^{\circ} \mathrm{C}$ on mortar, and 2.7 $\mathrm{mm}, 7.5-\mathrm{mm}$, and $12-\mathrm{mm}$ plywood finishing, respectively.

This study focused on buttock responses. Compared with the works of Fanger ${ }^{5}$ and Olesen ${ }^{6}$, the skin temperature changes of the sole were similar to those of the buttocks. Under an extreme cold or hot conditions, the thicker the wood finishing is, the less damage there can be because heat loss or heat gain of the human body decreases.

Subjective thermal sensation and comfort

Figure 4 shows the changes in subjective thermal sensation on the buttocks using a 9-point rating scale that ranged from 0 (very cold) to 8 (very hot). In the case of $t_{\mathrm{sw}} 15^{\circ} \mathrm{C}$ on mortar finishing, participants agreed that the thermal sensation of the buttocks was cold; at $t_{\mathrm{sw}} 40^{\circ} \mathrm{C}$, it was regarded as warm. On 2.7- and 7.5-mm plywood covering, it was rated cool to slightly warm. On $12-\mathrm{mm}$ plywood, it was considered slightly cool to slightly warm. Compared with mortar finishing at $t_{\mathrm{sw}} 15^{\circ} \mathrm{C}, t_{\mathrm{f}}$ changed from $17.0^{\circ}$ to $19.1^{\circ} \mathrm{C}$ and the thermal sensation changed from cold to slightly cool.

The patterns of thermal sensation changes were similar to the buttock temperature changes, because human skin perceives thermal sensation. Although many researchers have suggested the comfortable surface temperature for various finishing materials, the skin temperature of the human body is one of the most reliable indices of thermal sensation.

Regression analysis was performed to obtain an equation that can calculate the thermal comfort index of buttocks. Equations obtained in the regression analysis are as follows:

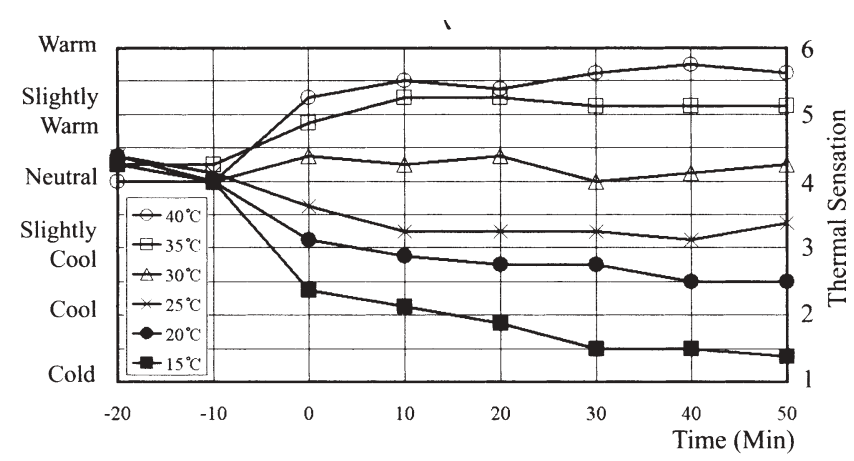

(1) On Mortar Finishing, Thermal Sensation Vote

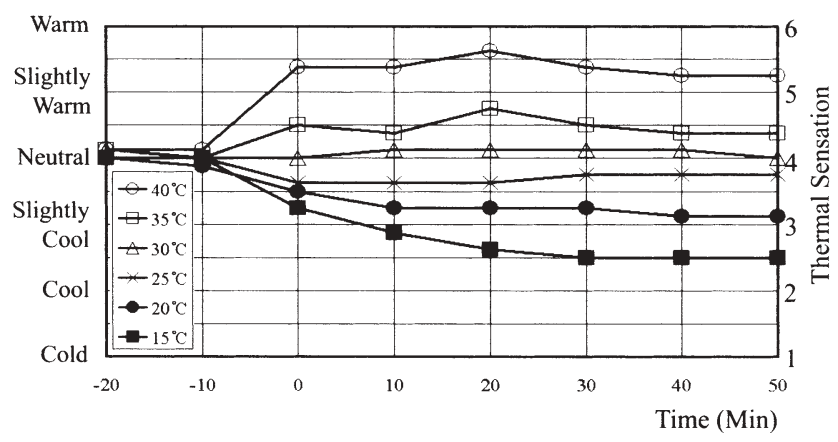

(2) On $2.7 \mathrm{~mm}$ Plywood Covering, Thermal Sensation Vote

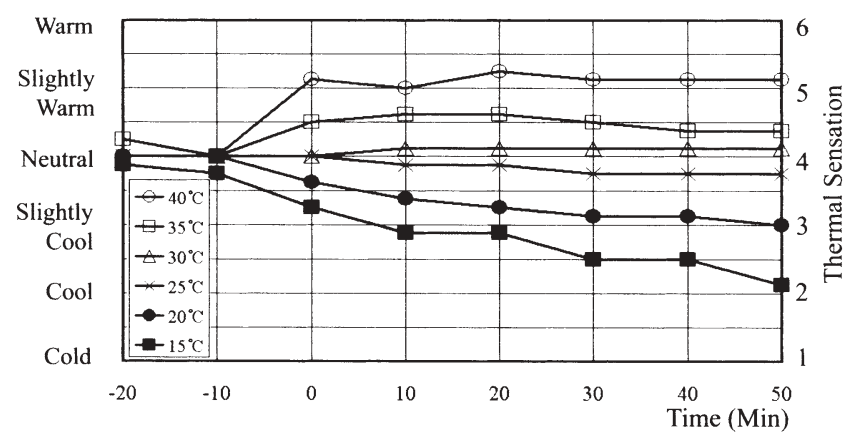

(3) On $7.5 \mathrm{~mm}$ Plywood Covering, Thermal Sensation Vote

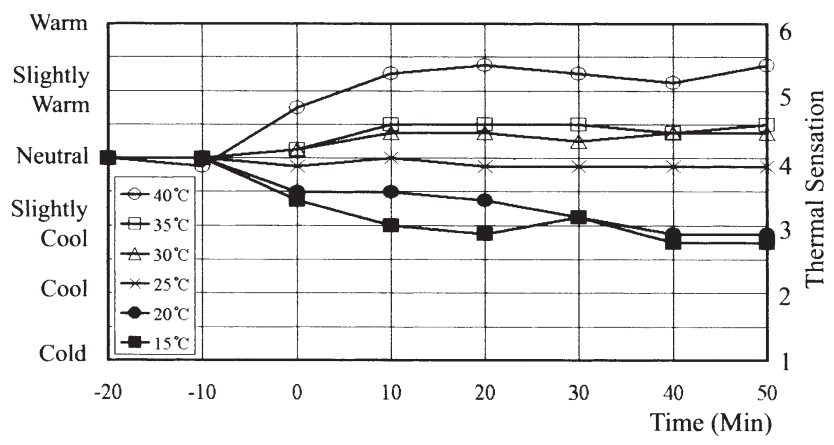

(4) On 12mm Plywood Covering, Thermal Sensation Vote

Fig. 4. Changes of subjective thermal sensation vote on buttocks 


$$
y=0.351 x-7.516\left(R^{2}=0.637\right) \quad(\text { for men and women) }
$$

where $y$ is the thermal sensation and $x$ is the buttock skin temperature.

$$
\begin{aligned}
& y=0.309 x-6.174 \quad\left(R^{2}=0.539\right) \quad(\text { for men }) \\
& y=0.386 x-8.643 \quad\left(R^{2}=0.671\right) \quad(\text { for women) }
\end{aligned}
$$

The neutral point temperature of buttocks was determined to be $32.8^{\circ} \mathrm{C}$ for men and women, and $32.8^{\circ} \mathrm{C}$ for men and $32.9^{\circ} \mathrm{C}$ for women. There was no significant difference between men and women.

\section{Conclusions}

This study investigated the skin response of the buttocks and the floor surface temperature of plywood flooring, of varied thickness, over the ONDOL heating system. Although the temperature of the supply water was the same, the floor surface temperature and skin temperature of buttocks varied depending on the thickness of the covering material. The thicker the plywood covering, the narrower the temperature fluctuations for floor surface and buttock skin were. The human body should be comfortable as a whole. If one part is not thermophysiologically at ease, a heating or cooling system should be procured for that part. At sedentary posture, ambient air as well as the floor surface temperature influence thermal comfort. Because a comfortable temperature range is different depending on the finishing material and its thickness, this should be taken into consideration in the design of a floor-heating system. During mild seasons such as spring and autumn, the heating system should be used on floors with mortar finishing. If it is finished with wood, however, heating is not required. Therefore, buttock temperature is a reliable index to evaluate the thermal comfort of a person at sedentary posture.
As such, it should be taken into consideration in floor system design.

Acknowledgments This work was supported by a grant No. R05-2002001044-0 from Korea Science \& Engineering Foundation.

\section{References}

1. Chen F (1997) Thermal responses of the hand to convective and contact cold - with and without gloves. PhD thesis, Department of Industrial Ergonomics, Linkoping University, Sweden.

2. Lawrence JC, Bull JP (1976) Thermal conditions which cause skin burns, IMechE 5(3):61-63

3. Wang S-Y, Kuo P-W (1995) Changes of skin temperatures as feet contacted floors constructed of different materials (in Japanese). Mokuzai Gakkaishi 41:731-740

4. Wang S-Y, Lin F-C, Lin M-Y (2001) Thermal properties of interior decorating material and the sensation of cold/warm by contact II: the relations among heat flux, temperature change of material, and sensation of cold/warm by contact. J Wood Sci 47:109-114

5. Banhidi LJ (1991) Radiant heating systems design and applications. Pergamon, Oxford, pp 297-305

6. Olesen BW (1977) Thermal comfort requirements for floors occupied by people with bare feet, ASHRAE transactions No. 2451, pp 41-57

7. Fanger PO (1970) Thermal comfort analysis and applications in environmental engineering. Danish Technical, Copenhagen, p 102

8. Song G-S (2001) At sedentary posture, thermal comfort comparison between floor finishing materials. Proceedings of 25th Symposium on Human-Environment System, Okinawa, pp 242-245

9. Mochita T, Shimakura K, Yoshida N (1994) Comparison of formulas for calculating average skin temperature and their characteristics. Ann Physiol Anthrop 13:357-373

10. Lee J-Y, Miyamoto S, Isoda N (2000) New weighting coefficients for calculating mean skin temperature in relation to the posture with consideration to heat conduction. J Ergon Soc Korea 19:63-74

11. Yoon H-S (1992) A study on the local discomfort by contact with floors in Korean panel heating system (in Korean). Ph.D. Thesis, Youngnam University, p 133

12. Modera MP (1993) Skin temperature and evaporative heat loss variations for men and women in thermal comfort. ASHRAE Trans 99:210-222

The publication of this article was made possible by an Emachu Research Fund. The author is greatful for the fund. 